\title{
EROSÃO HÍDRICA, EM TRÊS MOMENTOS DA CULTURA DO MILHO, INFLUENCIADA POR MÉTODOS DE PREPARO DO SOLO E SEMEADURA ${ }^{(1)}$
}

\author{
Leandro Bochi da Silva Volk ${ }^{(2)} \&$ Neroli Pedro Cogo ${ }^{(3)}$
}

\begin{abstract}
RESUMO
Independentemente do sistema de preparo, as condições superficiais do solo que regem o processo erosivo pela água da chuva se alteram durante o desenvolvimento da cultura de milho. Ao mesmo tempo, as condições físicas de superfície do solo que maneam as perdas de solo são distintas das que conduzem as perdas de água por erosão. A hipótese desta pesquisa foi que essas alterações ocorridas durante o desenvolvimento da cultura do milho reduziriam as perdas de solo, mas não alterariam as perdas de água por erosão. Com base nisso, realizou-se este trabalho com o objetivo de avaliar o efeito de diferentes condições físicas de superfície do solo, criadas por métodos de seu preparo, nas perdas de solo e água por erosão hídrica (causada por chuva simulada), em três momentos de crescimento da cultura do milho. O estudo foi desenvolvido na EEA/UFRGS, município de Eldorado do Sul, RS, em Argissolo Vermelho distrófico típico, com textura franco-argiloarenosa no horizonte A e declividade média de $0,08 \mathrm{~m} \mathrm{~m}^{-1}$. Os tratamentos estudados, estabelecidos sobre resíduos culturais (recém-colhidos) de aveia-preta, foram: preparo convencional (uma aração+duas gradagens - $\mathrm{A}+2 \mathrm{G}$ ), preparo reduzido 1 (uma escarificação+uma gradagem $\mathrm{E}+\mathrm{G}$ ), preparo reduzido 2 (apenas uma escarificação - E), semeadura direta 1 (semeadora-adubadora provida de facões ou hastes sulcadoras para colocação do fertilizante na profundidade de $12 \mathrm{~cm}$ - SDf), semeadura direta 2 (semeadoraadubadora desprovida de hastes sulcadoras, mas contendo discos-duplos desencontrados para colocação das sementes na profundidade de $5 \mathrm{~cm}$ - SDd) e tratamento testemunha (preparo convencional - aração+duas gradagens -, porém sem cultivo do solo - parcela padrão ou unitária - T), seguidos da semeadura do
\end{abstract}

(1) Trabalho realizado com recursos financeiros do Projeto CNPq-PRONEX/Solos e do Auxílio "grant"/CNPq, e com o apoio de bolsistas de iniciação científica dos Programas PIBIC-CNPq/UFRGS, CNPq e FAPERGS. Recebido para publicação em 27 de abril de 2013 e aprovado em 6 de janeiro de 2014.

(2) Pesquisador A, Centro de Pesquisa de Pecuária dos Campos Sul-Brasileiros - Embrapa. BR 153, km 633, Vila Industrial. Caixa Postal 242. CEP 96401-970 Bagé (RS). Ex-bolsista CAPES. E-mail: leandro.volk@embrapa.br

(3) Professor Associado, Departamento de Solos, Faculdade de Agronomia, UFRGS. Av. Bento Gonçalves, 7712 . Caixa Postal 15100. CEP 91501-970 Porto Alegre (RS). Bolsista do CNPq. E-mail: neroli@ufrgs.br 
milho (exceto o tratamento T). A avaliação das perdas de solo e água por erosão foi feita por meio da aplicação de três chuvas simuladas (simulador de braços rotativos), na intensidade de $64 \mathrm{~mm} \mathrm{~h}^{-1}$ e com duração de 120 min cada uma, nos seguintes momentos da cultura do milho: logo após a semeadura; aos 45 e aos 116 dias, após a primeira aplicação de chuva. A rugosidade superficial do solo criada pela escarificação retardou o início da enxurrada e aumentou a infiltração de água, consideravelmente diminuindo a perda dessa última por erosão, enquanto a cobertura por resíduos culturais expressivamente reduziu a perda de solo. A máquina de semeadura direta provida de facões ou hastes sulcadoras mobilizou o solo mais do que a desprovida desses órgãos (equipada apenas com sulcadores tipo discos-duplos desencontrados), diminuindo a perda de água ao redor de 35 \% e mantendo a perda de solo pequena. No solo preparado convencionalmente e com cultivo, em razão do processo natural de reconsolidação e da cobertura gradual oferecida pelas plantas de milho, a perda de solo foi maior no início da cultura, enquanto a perda de água foi maior no seu final.

Termos de indexação: chuva simulada, semeadura direta, escarificação, rugosidade superficial do solo, cobertura superficial do solo, perda de solo, perda de água.

\title{
SUMMARY: WATER EROSION AT THREE MOMENTS IN THE CORN CROP, AFFECTED BY SOIL TILLAGE AND CROP SOWING $M E T H O D S$
}

\begin{abstract}
Apart from the soil tillage system, the soil surface conditions that govern the rainwater erosion process change during growth of the corn crop. At the same time, the physical conditions of the soil surface that govern soil losses are different from those that govern water losses by erosion. The hypothesis of this study is that these changes occurring during the growth of the corn crop reduce soil losses but do not reduce water losses by erosion. Based on that, this study was carried out with the aim of evaluating the effect of different soil surface physical conditions, created by tillage methods, on soil and water losses by water erosion (caused by simulated rainfall), at three moments of the corn crop. The study was developed in the field at the EEA/ UFRGS in the municipality of Eldorado do Sul, Rio Grande do Sul, Brazil, on an Argissolo Vermelho distrófico típico (Acrisol) with sandy clay loam texture in the A horizon, and 0,08 $\mathrm{m} \mathrm{m}^{-1}$ average slope. The treatments under study, established on (newly harvested) black oat crop residues were: conventional tillage (one plowing+two diskings - $A+2 G$ ); reduced tillage 1 (one chiseling+one disking - E+G); reduced tillage 2 (one chiseling only - E); no-tillage 1(no-till planter-fertilizer equipped with furrowing shafts or shanks for placing fertilizer at a $12 \mathrm{~cm}$ soil depth - SDf); no-tillage 2 (no till planter-fertilizer having no shafts or shanks, but equipped with double-disk openers for placing the seeds at a $5 \mathrm{~cm}$ soil depth - SDd); and control treatment (conventional tillage - one plowing+two diskings but in continuous fallow - unit or standard plot - T), followed by sowing the corn (except for treatment T). Soil and water losses by erosion were evaluated by applying three simulated rainfalls (rotating-boom simulator), each of them at an intensity of $64 \mathrm{~mm} \mathrm{~h}^{-1}$ of 120 min duration, at the following moments of the corn crop: immediately after sowing; at 45 days; and at 116 days after sowing. Soil surface roughness created by chiseling delayed surface runoff and increased water infiltration, considerably reducing water loss by erosion, while surface cover by crop residues significantly reduced soil loss. The no-till planter equipped with furrowing shafts or shanks disturbed the soil more than the one without them (equipped with only double-disk openers), decreasing water loss by about $35 \%$ and minimizing soil loss. In the conventionally tilled and planted soil, due to both the natural reconsolidation process and the gradual soil cover offered by corn plants, soil loss by erosion was greater at the beginning of cropping, while water loss was greater at the end.
\end{abstract}

Index terms: simulated rainfall, no-tillage, chisel-plowing, soil surface roughness, soil surface cover, soil loss, water loss. 


\section{INTRODUÇÃO}

Fundamentalmente, o processo de erosão hídrica do solo é determinado pela combinação do regime de chuva, do tipo de solo, das características do relevo, das práticas de manejo e das práticas conservacionistas de suporte (Wischmeier \& Smith, 1978). Entre as práticas de manejo que diretamente influenciam o processo erosivo causado pela água da chuva, as operações de preparo do solo e semeadura das culturas ganham destaque, uma vez que elas determinam as condições físicas de superfície e subsuperfície dele. As operações de preparo do solo e semeadura das culturas geralmente aumentam sua rugosidade superficial, principalmente a orientada (Cogo et al, 1983; Castro et al., 2006), aumentando a porosidade total da camada de solo preparada (Burwell et al., 1963; Cogo et al., 1983; Kay \& Van den Bygaart, 2002) e diminuindo a cobertura por resíduos culturais (Cogo et al., 1983). Volk et al. (2004) destacaram a importância dessas condições físicas superficiais do solo no processo erosivo, principalmente seu efeito diferenciado nas perdas de solo e água.

A rugosidade superficial do solo, especialmente a induzida por métodos de preparo, cria microdepressões que são fundamentais para o armazenamento da água da chuva e, desse modo, para o aumento de sua infiltração nele, retardando o início da enxurrada e, em consequência, reduzindo o escoamento superficial e sua capacidade de erodir o solo. Em adição, essa rugosidade superficial força o aprisionamento dos sedimentos da erosão nas microdepressões criadas por ela, induzindo sua deposição na área de ocorrência do fenômeno, possibilitando ainda mais a redução das perdas de solo (Burwell et al., 1963; Cogo et al., 1983; Levien et al., 1990; Volk \& Cogo, 2009; Luciano et al., 2009).

A magnitude de alteração das condições de superfície e subsuperfície do solo, contudo, vai depender do tipo de equipamento e método usado no seu preparo, o que influencia diferentemente as perdas de solo e água por erosão hídrica (Cogo et al., 1983; Castro et al., 2006). Em comparação com preparo convencional, o método sem preparo do solo ou de semeadura direta resulta em menor mobilização do solo (apenas o necessário para se colocar nele as sementes ou partes vegetativas das plantas), causando pouca ou nenhuma alteração na sua cobertura por resíduos culturais e com sua rugosidade superficial resultando em grau mínimo ou praticamente nulo. O método de preparo reduzido do solo, com a escarificação sendo uma de suas principais representantes, resulta em mobilização da sua camada, que pode chegar aos 40 $\mathrm{cm}$ de profundidade, com baixo grau de fragmentação dos agregados. Isso diminui a cobertura por resíduos culturais superficiais em menor grau do que o preparo convencional, causando rugosidade superficial em grau maior do que os demais métodos de preparo. $\mathrm{O}$ método de preparo convencional do solo (usualmente uma aração seguida de duas gradagens) resulta na mobilização completa de sua camada superficial (15-
$20 \mathrm{~cm}$ ), com elevado grau de fragmentação dos torrões e agregados, diminuindo muito a cobertura por resíduos culturais e deixando a rugosidade superficial e a porosidade total da camada preparada com valores intermediários entre o preparo reduzido (como na escarificação) e a semeadura direta (Burwell et al., 1966; Johnson et al., 1979; Bertol et al., 1987; Volk et al., 2004; Castro et al., 2006; Volk \& Cogo, 2009).

No caso específico do método sem preparo do solo ou de semeadura direta, as condições físicas de sua superfície, como descritas (baixa rugosidade superficial e alta cobertura por resíduos culturais), determinam valores pequenos de perda de solo, porém podem acarretar valores grandes de perda de água, durante o processo erosivo (Cogo, 1981; Bertol et al., 1987; Volk et al., 2004; Castro et al., 2006; Volk \& Cogo, 2009). Além do uso de práticas conservacionistas de suporte, uma alternativa para minimizar a perda de água por erosão em áreas cultivadas com a técnica de semeadura direta é aumentar a infiltração da água da chuva no solo, por meio da alteração de suas condições físicas de superfície e subsuperfície. Tal alteração pode ser conseguida por meio de eventuais escarificações do solo (Camara \& Klein, 2005; Klein et al., 2009), que, comprovadamente, reduzem a perda de água por erosão hídrica (Gilles et al., 2009), ou então pelo uso de órgãos ativos nas máquinas semeadoras-adubadoras. As semeadoras-adubadoras de semeadura direta podem ser providas de diferentes órgãos ativos para incorporação dos adubos, como hastes sulcadoras e discos-duplos desencontrados, que promovem diferentes alterações na superfície do solo (Herzog et al., 2004) e podem favorecer em graus diferenciados a infiltração da água da chuva nele.

Contudo, independentemente do sistema de preparo, as condições superficiais do solo que regem o processo erosivo pela água da chuva se alteram durante o desenvolvimento da cultura de milho. Assim, a hipótese deste estudo foi que as alterações ocorridas durante o desenvolvimento da cultura do milho reduzissem as perdas de solo, mas não alterassem as perdas de água por erosão. Com base nisso, realizouse este trabalho com o objetivo de avaliar o efeito de diferentes condições físicas de superfície do solo, criadas por métodos de seu preparo, nas perdas de solo e água por erosão hídrica (causada por chuva simulada), em três momentos de crescimento da cultura do milho.

\section{MATERIAL E MÉTODOS}

O estudo foi desenvolvido na Estação Experimental Agronômica da Universidade Federal do Rio Grande do Sul (EEA/UFRGS), em Eldorado do Sul, RS, na região fisiográfica da Depressão Central. Segundo a classificação de Köppen, o clima dessa região é do tipo "Cfa" - subtropical úmido sem estação seca definida. O solo da área experimental é classificado como 
Argissolo Vermelho distrófico típico (Embrapa, 2006), apresentando textura franco-argiloarenosa no horizonte A, drenagem moderada, declividade média de $0,08 \mathrm{~m} \mathrm{~m}^{-1}$ e profundidade efetiva inferior a $80 \mathrm{~cm}$.

Os tratamentos foram dispostos em pares de parcelas de erosão, envolvendo diferentes métodos de preparo do solo e semeadura do milho (Zea mays L.), como especificado a seguir. Os tratamentos foram implantados logo após a colheita da cultura de aveiapreta, cujo resíduo cultural permaneceu sobre as parcelas experimentais, e consistiram de: aração+duas gradagens $(\mathrm{A}+2 \mathrm{G})$; escarificação+uma gradagem $(\mathrm{E}+\mathrm{G})$; somente escarificação (E); semeadura direta com semeadora-adubadora provida de facões ou hastes sulcadoras (para colocação dos adubos na profundidade de $12 \mathrm{~cm}$ ) e de sulcadores tipo discos-duplos desencontrados (para colocação das sementes na profundidade de $5 \mathrm{~cm}$ - SDf); semeadura direta com semeadora-adubadora desprovida de facões ou hastes sulcadoras (o adubo foi depositado na superfície), mas portando os sulcadores tipo discos-duplos desencontrados (para colocação das sementes na profundidade de $5 \mathrm{~cm}$ SDd); e aração+duas gradagens, sem cultivo do solo parcela padrão/unitária ou tratamento testemunha (T). Nos tratamentos A+2G, E+G e E, após o preparo do solo, foi realizada a semeadura do milho, usando a semeadora-adubadora na mesma configuração do tratamento SDf e descrita a seguir.

O preparo convencional (utilizado nos tratamentos $\mathrm{A}+2 \mathrm{G}$ e $\mathrm{T}$ ) consistiu de uma aração, com arado reversível de três discos (lisos), com $76 \mathrm{~cm}$ de diâmetro cada um, em velocidade próxima a $4,5 \mathrm{~km} \mathrm{~h}^{-1}$, seguida de duas gradagens, com grade tipo niveladora (excêntrica), com 36 discos (lisos), com $54 \mathrm{~cm}$ de diâmetro um, em velocidade próxima a $5,0 \mathrm{~km} \mathrm{~h}^{-1}$, ambos os equipamentos operando na profundidade efetiva de $20 \mathrm{~cm}$. A escarificação (utilizada nos tratamentos $\mathrm{E}+\mathrm{G}$ e E) foi executada com escarificador de hastes parabólicas, providas de ponteiras estreitas, em número de cinco, com $6 \mathrm{~cm}$ de largura cada uma, espaçadas uma da outra de $45 \mathrm{~cm}$ e operando na profundidade efetiva de solo de $25 \mathrm{~cm}$, em velocidade próxima a $4,0 \mathrm{~km} \mathrm{~h}^{-1}$. Esse último equipamento portava um rolo destorroador em sua parte traseira, com o propósito de dar melhor acabamento à preparação do leito de semeadura da cultura. A gradagem realizada (imediatamente) após a escarificação (tratamento $\mathrm{E}+\mathrm{G}$ ) foi feita com a mesma grade usada no preparo convencional. A operação de semeadura, em todos os tratamentos (exceto nos Te SDd), foi realizada com semeadora-adubadora de semeadura direta de nove linhas, espaçadas entre si de $45 \mathrm{~cm}$, com discos-duplos desencontrados, para as funções de corte da palha e colocação das sementes no solo na profundidade de $5 \mathrm{~cm}$, seguidos de facões ou hastes sulcadoras (2 cm de largura cada uma), que operaram no solo na profundidade de $12 \mathrm{~cm}$. No caso do tratamento SDd, a semeadora-adubadora foi a mesma usada nos demais tratamentos, porém sem as hastes sulcadoras.
As operações de preparo do solo e semeadura do milho, em todos os tratamentos, foram realizadas com o solo encontrando-se na faixa de friabilidade, bem como no sentido do declive do terreno, conforme filosofia de obtenção do fator C - cobertura e manejo dos modelos "USLE" e "RUSLE" de predição da erosão hídrica (Wischmeier \& Smith, 1978; Renard et al., 1997).

O milho foi semeado no espaçamento de $45 \mathrm{~cm}$ entre suas fileiras, com população esperada de 60.000 plantas por hectare.

Para a avaliação das perdas de solo e água por erosão hídrica, foram efetuados três ensaios (testes de erosão) com chuva simulada, na intensidade constante de $64 \mathrm{~mm} \mathrm{~h}^{-1}$ e com duração de $120 \mathrm{~min}$ cada um, nos seguintes momentos durante o desenvolvimento da cultura do milho: Teste 1, imediatamente após as operações de preparo do solo e semeadura da cultura do milho (03/12/2004); Teste 2, 45 dias após a primeira aplicação de chuva (17/01/ 2005); e Teste 3, 116 dias após a primeira aplicação de chuva (30/04/2005). Para a aplicação das chuvas simuladas, empregou-se o aparelho simulador tipo de braços rotativos ou modelo Swanson (Swanson, 1965), que asperge água (jato em leque ou tipo V invertido) simultaneamente em duas parcelas experimentais, que (o par) foram usadas como repetições dos tratamentos. Essas parcelas mediam 3,5 m de largura por $11 \mathrm{~m}$ de comprimento cada uma, afastadas uma da outra de $3,5 \mathrm{~m}$, com a maior dimensão sendo disposta no sentido da pendente do terreno, conforme recomendações de Embrapa (1975).

A perda total da água da chuva, na forma de enxurrada, e a do solo, foram obtidas integrando-se, respectivamente, os valores da taxa de descarga da enxurrada e da concentração de sedimentos na enxurrada obtidos durante a aplicação das chuvas. A taxa de descarga da enxurrada foi alcançada pela medição direta da enxurrada após o seu início, e até o seu final, com proveta graduada e cronômetro, a cada três min. A concentração dos sedimentos na enxurrada foi determinada pela secagem (em estufa a $60^{\circ} \mathrm{C}$ ) de amostras de 1,0 L dessa, coletadas no mesmo instante da avaliação da sua taxa de descarga (Cogo, 1981).

A cobertura do solo por resíduo cultural (aveiapreta) foi determinada pelo uso de uma corda com comprimento de 11,5 m e marcada com 100 pontos esticada sobre a sua superfície, onde cada ponto coincidente com presença de cobertura (palhada ou folhas) foi considerado como 1 ponto percentual de cobertura (Hartwig \& Laflen, 1978). A rugosidade superficial do solo (orientada e ao acaso) foi avaliada utilizando-se um perfilômetro similar ao descrito por Küipers (1957), porém adaptado às condições do estudo. Tal equipamento possuía 2,60 m de largura e 0,55 m de altura, com 100 varetas linearmente espaçadas $2,5 \mathrm{~cm}$ uma da outra, possibilitando a tomada de 100 leituras de elevações da superfície do solo, longitudinalmente, no terço central de cada parcela, totalizando 200 leituras por tratamento. O método de 
cálculo usado na medição da rugosidade superficial do solo foi o do índice de rugosidade georreferenciado, como sugerido por Castro et al. (2000).

Os resultados foram submetidos à análise da variância, empregando-se o teste de comparação de médias de Duncan, a 10 \%, utilizando o programa computacional ESTAT (Sistema para Análises Estatísticas, v.2.0), desenvolvido pelo Polo Computacional do Departamento de Ciências Exatas da FCAV/UNESP, Jaboticabal, SP. O modelo matemático usado para estabelecer correlação entre as variáveis foi com base naquele que melhor descreveu o fenômeno da erosão; já o grau de significância dos ajustes dos modelos matemáticos, no método proposto por Fischer \& Yates (1971).

\section{RESULTADOS E DISCUSSÃO}

Em relação às alterações causadas superficialmente pelos diferentes métodos de preparo do solo utilizados neste estudo, a primeira a ser relatada refere-se à taxa de cobertura proporcionada pelos resíduos culturais de aveia-preta. A massa de resíduo cultural da aveiapreta presente em todos os tratamentos antes do preparo do solo era semelhante, resultando em taxa de cobertura desse também semelhante, exceto no tratamento testemunha (T), que não foi cultivado e, portanto, não possuía cobertura superficial (Quadro 1). A intensidade do preparo influenciou a taxa de cobertura do solo, onde o preparo mais intenso $(A+2 G)$ foi o que reduziu mais a taxa de cobertura, após o preparo e antes do Teste 1 . A incorporação parcial ou total do resíduo cultural por ocasião dos preparos de solo nos tratamentos com preparo convencional (A+2G) e preparo mínimo $(\mathrm{E}+\mathrm{G})$ reduziu a taxa de cobertura superficial em 86 e 56 \%, respectivamente. Já no tratamento com escarificação (E), em que também houve preparo do solo, mas sem incorporação do resíduo cultural, a cobertura permaneceu elevada, a exemplo dos tratamentos com semeadura direta (SDf e SDd). Da avaliação feita antes do Teste $3 \mathrm{em}$ diante, a cobertura do solo não diferiu mais entre os tratamentos.

A segunda alteração nas condições físicas superficiais do solo refere-se à sua rugosidade. $\mathrm{O}$ índice de rugosidade superficial (IR) avaliado antes do preparo do solo e da semeadura do milho apresentou valores pequenos (média de 0,4 cm) e semelhantes em todos os tratamentos (Figura 1), retratando a condição inicial desses.

Em relação à rugosidade superficial inicial, as operações de preparo e semeadura mobilizaram o solo e aumentaram o IR em todos os tratamentos, porém

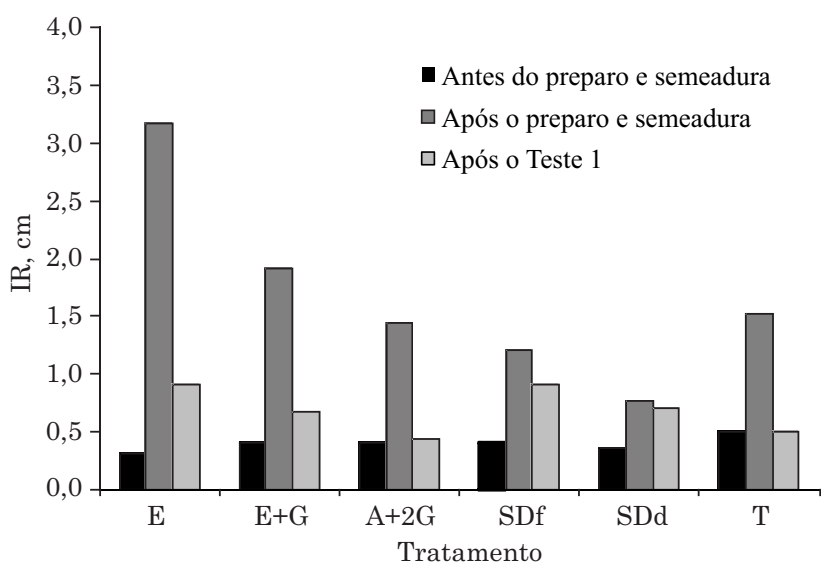

Figura 1. Índice de rugosidade superficial do solo (IR) medido antes e após as operações de preparo e semeadura e após a realização do primeiro teste de erosão (Teste 1) com chuva simulada.

Quadro 1. Quantidade de resíduo cultural de milho e equivalente porcentagem de cobertura do solo, avaliadas antes e após as operações de preparo e semeadura e antes da realização dos testes de erosão com chuva simulada, nos tratamentos estudados

\begin{tabular}{|c|c|c|c|c|c|}
\hline \multirow[b]{2}{*}{ Tratamento } & \multirow[b]{2}{*}{$\begin{array}{l}\text { Quantidade } \\
\text { de resíduo } \\
\text { cultural }^{(1)}\end{array}$} & \multicolumn{4}{|c|}{ Cobertura do solo } \\
\hline & & $\begin{array}{l}\text { Antes do } \\
\text { preparo }^{(1)}\end{array}$ & $\begin{array}{c}\text { Após o preparo } \\
\text { e antes } \\
\text { do Teste } 1^{(1)}\end{array}$ & $\begin{array}{l}\text { Antes do } \\
\text { Teste } 2^{(2)}\end{array}$ & $\begin{array}{l}\text { Antes do } \\
\text { Teste } 3^{(2)}\end{array}$ \\
\hline & $\mathrm{kg} \mathrm{ha} \mathrm{h}^{-1}$ & & $\%$ & 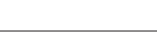 & 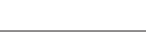 \\
\hline Escarificação (E) & $6.374 \mathrm{a}$ & $99 \mathrm{a}$ & $69 \mathrm{~b}$ & $79 \mathrm{~b}$ & $99 \mathrm{a}$ \\
\hline Escarif.+1gradagem $(\mathrm{E}+\mathrm{G})$ & $5.230 \mathrm{a}$ & $98 \mathrm{a}$ & $43 \mathrm{c}$ & $53 \mathrm{c}$ & $95 \mathrm{a}$ \\
\hline Aração+2 gradag. $(A+2 G)$ & $6.482 \mathrm{a}$ & $100 \mathrm{a}$ & $14 \mathrm{~d}$ & $40 \mathrm{c}$ & $95 \mathrm{a}$ \\
\hline Semeadura direta c/ facão (SDf) & $5.636 \mathrm{a}$ & $100 \mathrm{a}$ & $97 \mathrm{a}$ & $97 \mathrm{a}$ & $98 \mathrm{a}$ \\
\hline Sem. direta c/ disco (SDd) & $5.983 \mathrm{a}$ & $100 \mathrm{a}$ & $99 \mathrm{a}$ & $99 \mathrm{a}$ & $99 \mathrm{a}$ \\
\hline Padrão (T) & $0 \mathrm{~b}$ & $0 \mathrm{~b}$ & $0 \mathrm{e}$ & -(3) & - (3) \\
\hline
\end{tabular}

(1) Resíduo predominantemente de aveia-preta; ${ }^{(2)}$ cobertura do solo por resíduo de aveia-preta e dossel das plantas de milho;

(3) não avaliado, por não ter participado dos Testes 2 e 3 . Valores na coluna seguidos da mesma letra não diferem entre si pelo teste de Duncan a $10 \%$. 
em magnitudes diferentes. A escarificação foi o preparo mais eficaz em elevar o IR, como ocorreu no tratamento E, que apresentou o maior valor de IR $(3,3 \mathrm{~cm})$. No entanto, a gradagem realizada após a escarificação, como no tratamento $\mathrm{E}+\mathrm{G}$, diminuiu a eficácia dessa última, ocasionando menor aumento no IR $(1,9 \mathrm{~cm})$. O preparo do solo pelo método convencional também aumentou o IR, se comparado à condição inicial, como nos tratamentos $\mathrm{A}+2 \mathrm{G}$ e $\mathrm{T}$, porém em menor intensidade (1,4 e 1,2 cm, respectivamente). Nos tratamentos de semeadura direta (SDf e SDd), os valores de IR foram pouco alterados em relação à condição inicial, quando comparados com os demais tipos de preparo e semeadura. Contudo, no tratamento SDf, a atuação das hastes sulcadoras na profundidade de $12 \mathrm{~cm}$ resultou em valor de IR $75 \%$ maior do que na SDd. No entanto, após o Teste 1, em razão da elevada energia cinética das chuvas simuladas usadas no estudo, $1.704 \mathrm{MJ} \mathrm{mm} \mathrm{ha}^{-1} \mathrm{~h}^{-1}$, calculada pela equação de Wischmeier \& Smith (1958), houve redução dos valores de IR em todos os tratamentos. Essa redução da rugosidade superficial causada pela primeira chuva, ou seja, após o preparo do solo, também foi observada por Cogo et al. (1984), Eltz \& Norton (1997), Castro et al. (2006), Bertol et al. (2006) e Panachuki et al. (2010). Tal redução foi mais intensa nos tratamentos $\mathrm{A}+2 \mathrm{G}$ e $\mathrm{T}$, que retornaram aos valores inicias (antes do preparo e da semeadura). Já nos tratamentos com semeadura direta (SDf e SDd), a ação da chuva reduziu os valores de IR, porém em menor magnitude do que nos demais tratamentos, como também observado por Castro et al. (2006), Bertol et al. (2006) e Panachuki et al. (2010). Nos Testes 2 e 3, o IR não foi mais medido por causa da interferência das plantas de milho; contudo, considerando-se que não houve mais diferença entre os valores observados após o Teste 1 e que não houve mais nenhuma intervenção no solo para alterar sua rugosidade, assumiu-se que os valores de IR permaneceram constantes até o final do ciclo do milho.
Na figura 2a,b, são apresentados os valores dos tempos necessários para o início (tempo de empoçamento - Ti) e o equilíbrio da enxurrada (taxa de descarga constante - Te), respectivamente. Observa-se na figura 2 que, tanto Ti quanto Te, foram influenciados pelos métodos de preparo de solo utilizados no estudo. Em relação ao Ti, o tratamento apenas com escarificação (E), em razão da maior rugosidade superficial (Figura 1), foi o que mais retardou o início da enxurrada, tanto no primeiro quanto nos outros dois testes de erosão com chuva simulada, indicando que esse tipo de preparo melhora as condições para infiltração da água no solo, fato esse também observado por Gilles et al. (2009) e Portela et al. (2010).

Já a realização de uma gradagem após a escarificação (tratamento $\mathrm{E}+\mathrm{G}$ ) alterou a condição de rugosidade antes referida (alta), fazendo com que o solo apresentasse baixo valor de $\mathrm{Ti}$, indicando diminuição da capacidade de infiltração de água, e passasse a ter comportamento similar ao solo preparado convencionalmente (tratamento $\mathrm{A}+2 \mathrm{G}$ ). Esses dois tratamentos apresentaram maiores valores de Ti apenas no primeiro teste de chuva simulada, por causa da persistência da rugosidade superficial deles. No entanto, nos dois testes posteriores, com as plantas de milho em desenvolvimento, além da diminuição da rugosidade superficial observou-se a formação de sulcos, o que explica a acentuada redução em Ti. Assim, nos tratamentos A+2G e E+G, o efeito da rugosidade superficial do solo na retenção da água da chuva foi efêmero e durou apenas até a primeira chuva. Tal efeito foi também observado por Castro et al. (2006), Bertol et al. (2006) e Volk \& Cogo (2009).

A discussão dos valores de Ti nos tratamentos de semeadura direta (SDf e SDd) merece duas abordagens distintas. A primeira refere-se à comparação desses dois tratamentos com o tratamento em que o solo sofreu apenas escarificado (E). Comparando-os, observa-se que nos três testes com chuva simulada os

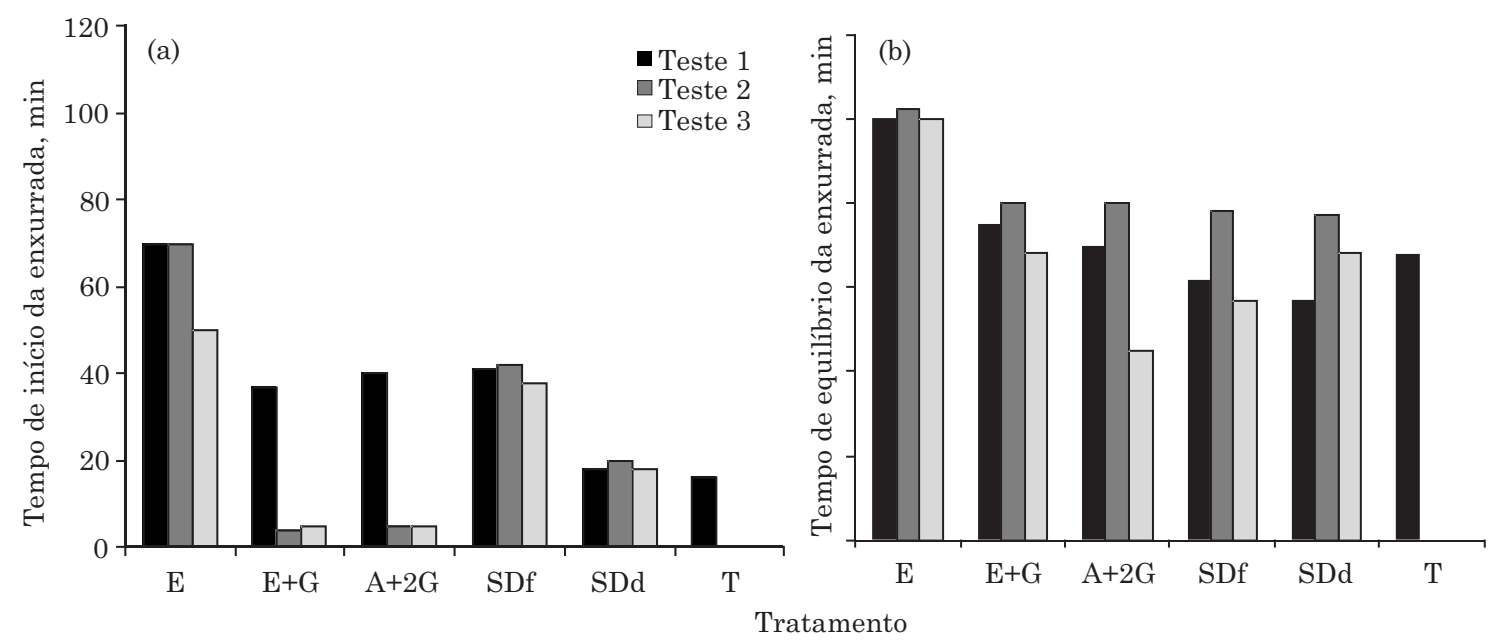

Figura 2. Tempos de início (a) e de equilíbrio (b) da enxurrada, medidos em cada teste de erosão (Teste 1, Teste 2 e Teste 3) com chuva simulada, nos tratamentos estudados. 
tratamentos SDf e SDd apresentaram menores valores de Ti - comportamento também observado por Mello et al. (2003) -, principalmente o tratamento SDd, que já no primeiro teste apresentou valores inferiores aos dos tratamentos com preparo convencional $(A+2 G)$ e escarificação + gradagem $(\mathrm{E}+\mathrm{G})$. Isso se explica, principalmente, pelos baixos valores de IR (Figura 1), resultantes da ausência de preparo e mobilização do solo. Ao mesmo tempo, a ausência de preparo e mobilização do solo nos tratamentos SDf e SDd resguardou as suas condições iniciais de estrutura e, consequentemente, de capacidade de infiltração de água. Por isso, a variação em Ti entre os três testes de erosão com chuva simulada foi muito pequena, fato esse não observado nos demais tratamentos com mobilização de solo. A segunda reporta-se à comparação apenas entre os dois tratamentos de semeadura direta. Nessa comparação, destacam-se os valores do tempo de início da enxurrada no tratamento SDf, que foram duas vezes maiores, em média, nos três testes de erosão hídrica realizados, comparados ao tratamento SDd. Assim, para o Argissolo do estudo, o uso de hastes sulcadoras na máquina semeadora-adubadora de semeadura direta retardou em 20 min o início da enxurrada, permitindo a retenção e infiltração de $21 \mathrm{~mm}$ de chuva a mais (considerando a intensidade de chuva de $64 \mathrm{~mm} \mathrm{~h}^{-1}$ utilizada neste estudo) do que na semeadura direta sem hastes sulcadoras.

Em relação ao tempo de equilíbrio da enxurrada (Te), cujos valores são apresentados na figura $2 b$, observa-se que no primeiro teste com chuva simulada os Tes foram tanto maiores quanto maiores foram os valores de IR (Figura 1). Assim, o tratamento com solo escarificado (E), que apresentou o maior IR após o preparo, foi o que evidenciou o maior atraso no tempo necessário para que a enxurrada atingisse seu valor máximo constante, permitindo a maior infiltração de água da chuva no estudo. Ao mesmo tempo, os tratamentos que apresentaram IR com valores intermediários e semelhantes entre si $(\mathrm{E}+\mathrm{G}, \mathrm{A}+2 \mathrm{G}$ e T) resultaram em Te com o mesmo comportamento (valores intermediários e semelhantes entre si). Os tratamentos de semeadura direta (SDf e SDd), por demonstrarem baixo IR, portanto sem o impedimento físico imposto pela rugosidade superficial para reter água da chuva, apresentaram os menores valores de Te observados no Teste 1 . No Teste 2 , os valores de Te ficaram muito semelhantes entre si em todos os tratamentos, com exceção do solo escarificado (tratamento E), que manteve seu valor alto. Ao mesmo tempo, todos os tratamentos evidenciaram valores de Te ligeiramente maiores do que os observados no Teste 1, possivelmente em razão da interceptação foliar promovida pelas plantas de milho. No Teste 3, o tratamento com solo escarificado foi novamente o que apresentou maior valor de Te, ficando o tratamento com preparo convencional $(\mathrm{A}+2 \mathrm{G})$ com o valor mais baixo.

No quadro 2, são apresentadas as perdas de solo e de água por erosão observadas nos tratamentos estudados, nos três testes de chuva simulada realizados. Observa-se que as perdas de solo variaram entre os tratamentos e testes de chuva. Por causa da elevada cobertura do solo por resíduos culturais (Quadro 1), os tratamentos de semeadura direta (SDf e SDd) apresentaram perdas de solo praticamente nulas nos três testes de chuva. O tratamento com escarificação (E), mesmo com elevado valor de IR (Figura 1) e alta taxa de cobertura superficial do solo após seu preparo (Quadro 2), apresentou perda de solo mensurável nos Testes 1 e 2 , mas estatisticamente semelhante aos tratamentos com semeadura direta (SDf e SDd). Já no Teste 3, esse tratamento passou a ter o efeito da cobertura do solo oferecido pelas plantas de milho, e a perda de solo então passou a ser praticamente nula. $\mathrm{O}$ uso de uma gradagem após a escarificação (tratamento $\mathrm{E}+\mathrm{G}$ ) foi suficiente para consideravelmente reduzir a cobertura do solo (Quadro 1) e o valor de IR (Figura 1) antes do Teste 1, o que aumentou a perda de solo em mais de seis vezes, comparada à do tratamento $\mathrm{E}$, em que não se efetuou gradagem. No teste seguinte (Teste 2), pelo fato de a cobertura do solo ter sofrido pouca alteração, a perda

Quadro 2. Perda total de solo e de água nos testes de erosão (Teste 1, Teste 2 e Teste 3) com chuva simulada, nos tratamentos estudados

\begin{tabular}{|c|c|c|c|c|c|c|c|c|}
\hline \multirow{2}{*}{ Tratamento } & \multicolumn{4}{|c|}{ Perda total de solo } & \multicolumn{4}{|c|}{ Perda total de água } \\
\hline & Teste 1 & Teste 2 & Teste 3 & Total & Teste 1 & Teste 2 & Teste 3 & Total \\
\hline & \multicolumn{4}{|c|}{$-\mathrm{Mg} \mathrm{ha}^{-1}$} & \multicolumn{4}{|c|}{ - \% da chuva } \\
\hline Escarificação (E) & $0,2 \mathrm{c}$ & $0,1 \mathrm{~b}$ & $\sim 0 \mathrm{a}$ & 0,3 & $17,1 \mathrm{c}$ & $21,3 \mathrm{~b}$ & $33,0 \mathrm{~b}$ & 23,8 \\
\hline Escarif.+gradagem $(\mathrm{E}+\mathrm{G})$ & $1,3 \mathrm{~b}$ & $1,3 \mathrm{a}$ & $0,3 \mathrm{a}$ & 2,9 & $20,2 \mathrm{c}$ & $31,1 \mathrm{~b}$ & $42,9 \mathrm{a}$ & 31,4 \\
\hline Aração+2 gradag. $(A+2 G)$ & $1,0 \mathrm{~b}$ & $1,7 \mathrm{a}$ & $0,1 \mathrm{a}$ & 2,8 & $23,5 \mathrm{c}$ & 50,5 a & $52,2 \mathrm{a}$ & 42,0 \\
\hline Semeadura direta c/ facão (SDf) & $\sim 0^{(1)} \mathrm{c}$ & $\sim 0 \mathrm{~b}$ & $\sim 0 \mathrm{a}$ & $\sim 0$ & $28,9 \mathrm{~b}$ & $22,2 \mathrm{~b}$ & $27,3 \mathrm{~b}$ & 26,1 \\
\hline Sem. direta c/ disco (SDd) & $\sim 0 \quad \mathrm{c}$ & $\sim 0 \mathrm{~b}$ & $\sim 0 \mathrm{a}$ & $\sim 0$ & $37,5 \mathrm{a}$ & $43,5 \mathrm{a}$ & $38,5 \mathrm{~b}$ & 39,8 \\
\hline Padrão (T) & $4,0 \mathrm{a}$ & $-(2)$ & $(2)$ & 4,0 & $42,1 \mathrm{a}$ & - & - & 42,1 \\
\hline
\end{tabular}

(1) A perda de solo foi tão pequena que não pode ser mensurada. Para a análise estatística, consideraram-se esses valores como "zero"; ${ }^{(2)}$ não avaliado, por não ter participado dos Testes 2 e 3. Valores na coluna seguidos da mesma letra não diferem entre si pelo teste de Duncan a $10 \%$. A umidade gravimétrica na profundidade de 0-10 cm foi: 0,09; 0,10 e 0,10 kg kg-1, nos Testes 1 , 2 e 3 , respectivamente. 
de solo se manteve em valor semelhante. Já no Teste 3 , em razão de as plantas de milho terem aumentado muito a cobertura do solo (passou de 53 para $95 \%$ ), a perda de solo reduziu. O tratamento com preparo convencional e solo cultivado $(\mathrm{A}+2 \mathrm{G})$ apresentou comportamento e valores semelhantes ao tratamento $\mathrm{E}+\mathrm{G}$, com perda de solo mensurável nos dois primeiros testes (Testes 1 e 2), por causa dos baixos valores de cobertura superficial e IR, tendo o valor dessa sensivelmente diminuído no último teste (Teste 3), em razão do aumento da cobertura do solo pelas plantas de milho. Contudo, todos os tratamentos apresentaram perda de solo inferior à do tratamento testemunha (T).

Em relação à perda de água, observou-se que nos tratamentos em que o solo foi mobilizado os valores dessa aumentaram do Teste 1 para o Teste 2 e deste para o Teste 3 , uma vez que os valores de IR também diminuíram entre eles. Esse mesmo comportamento não foi observado nos tratamentos de semeadura direta, tendo havido variação entre testes e tratamentos. Ao mesmo tempo, salientou-se que o uso de hastes sulcadoras na máquina semeadoraadubadora propiciou menor perda de água do que no tratamento sem elas (SDf), com uma redução média de $34 \%$, para os dois primeiros testes.

Somando as perdas de solo e de água dos três testes de chuva simulada realizados, nas diferentes fases de desenvolvimento da cultura do milho, tornou-se evidente que os tratamentos de semeadura direta (SDd e SDf) foram muito eficazes no controle da perda de solo, uma vez que ela resultou praticamente nula. Por sua vez, o tratamento com escarificação (E), apesar da elevada mobilização de solo nele, resultou em perda de solo muito pequena. Os tratamentos $\mathrm{E}+\mathrm{G}$ e $\mathrm{A}+2 \mathrm{G}$, com maior

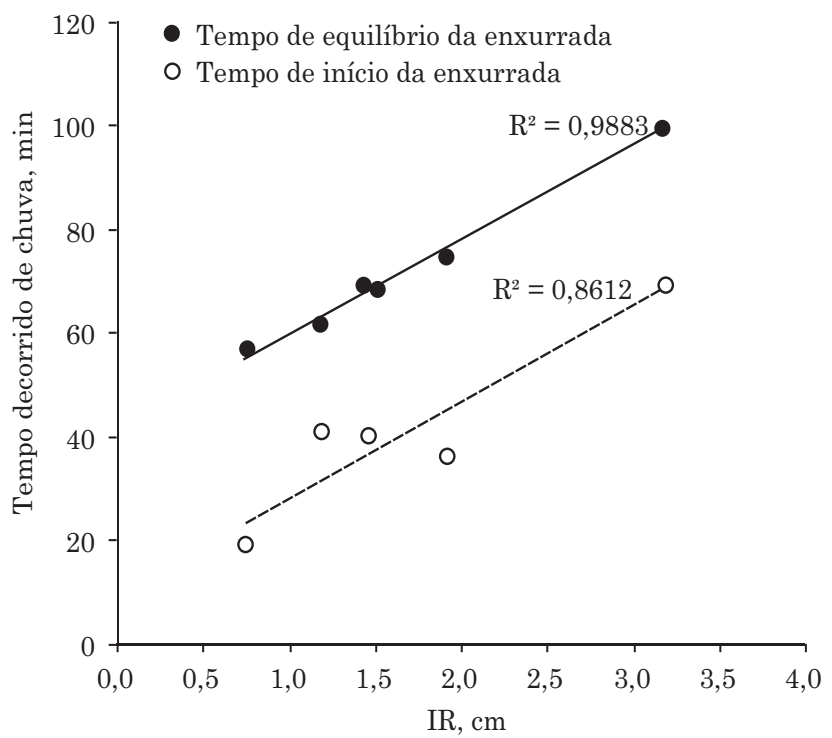

Figura 3. Relação dos tempos de início e equilíbrio da enxurrada medidos no primeiro teste de erosão (Teste 1), com chuva simulada, com o índice de rugosidade superficial do solo (IR) medido após o preparo do solo e a semeadura do milho. mobilização superficial de solo, portanto maior incorporação de resíduos culturais, resultaram em perda de solo semelhante entre si e inferior somente à observada no tratamento testemunha (T). Já a perda de água teve comportamento diferente, com os tratamentos de preparo convencional $(\mathrm{A}+2 \mathrm{G}$ e $\mathrm{T})$, sendo os que mais a perderam, enquanto a escarificação (tratamento E) foi a que perdeu menos. Quanto aos tratamentos de semeadura direta, o que continha hastes sulcadoras na máquina semeadora-adubadora (SDf), perdeu menos água por escoamento superficial do que o que não as tinham, mantendo o valor médio de $34 \%$ do total das chuvas aplicadas, como já relatado.

Considerando o período de cultivo do milho em que os testes de erosão com chuva simulada foram realizados, salientou-se que, em todos os tratamentos em que houve mobilização/preparo do solo (E, E+G e $\mathrm{A}+2 \mathrm{G}$ ), a perda desse foi maior nos dois primeiros testes (Testes 1 e 2), momentos em que o solo não havia ainda se reconsolidado naturalmente e não contava com a elevada cobertura oferecida pelas plantas de milho, como acontecido no Teste 3 . Essa constatação indicou que o período inicial de desenvolvimento da cultura é o que deixa o solo mais suscetível aos danos da erosão hídrica. Essa observação, contudo, não cabe nos tratamentos de semeadura direta, uma vez que a perda de solo nesses foi sempre praticamente nula. Já a perda de água da chuva na forma de enxurrada apresentou comportamento distinto. Assim, nos tratamentos em que o solo foi mobilizado/preparado os maiores valores de perda de água ocorreram no último teste de chuva simulada (Teste 3), momento em que o solo já se encontrava mais reconsolidado. Novamente, essas considerações não cabem nos tratamentos de semeadura direta.

Os tempos de início e equilíbrio da enxurrada observados no primeiro teste de chuva simulada (Teste 1, logo após o preparo do solo e a semeadura do milho) apresentaram relação direta e crescente com o índice de rugosidade superficial do solo (IR), significando que quanto maior o valor desse tanto maior o tempo de início $\left(\mathrm{R}^{2}=0,861\right)$ e o de equilíbrio da enxurrada $\left(\mathrm{R}^{2}=0,988\right)$. Os maiores tempos de início e equilíbrio da enxurrada resultaram em maior retenção e detenção superficiais da água da chuva; portanto, menor perda de água por escoamento superficial. Desse modo, os métodos de preparo do solo que propiciaram valores maiores de IR (Figura 1) apresentaram menor perda de água (Figura 2a). Contudo, cabe salientar que essa afirmação é válida, apenas, enquanto o índice de rugosidade superficial do solo permanecer elevado, ou seja, somente até a ocorrência da primeira chuva intensa após o preparo do mesmo. Para os Testes $2 \mathrm{e}$ 3 , as relações em pauta não foram desenvolvidas, uma vez que elas não se mantiveram $\left(R^{2}<0,2\right)$, indicando que já não era mais a rugosidade superficial do solo que governava a detenção superficial de água nele, para posterior infiltração nesse.

Na figura 4a,b, são apresentadas, respectivamente, as relações entre cobertura superficial do solo por 

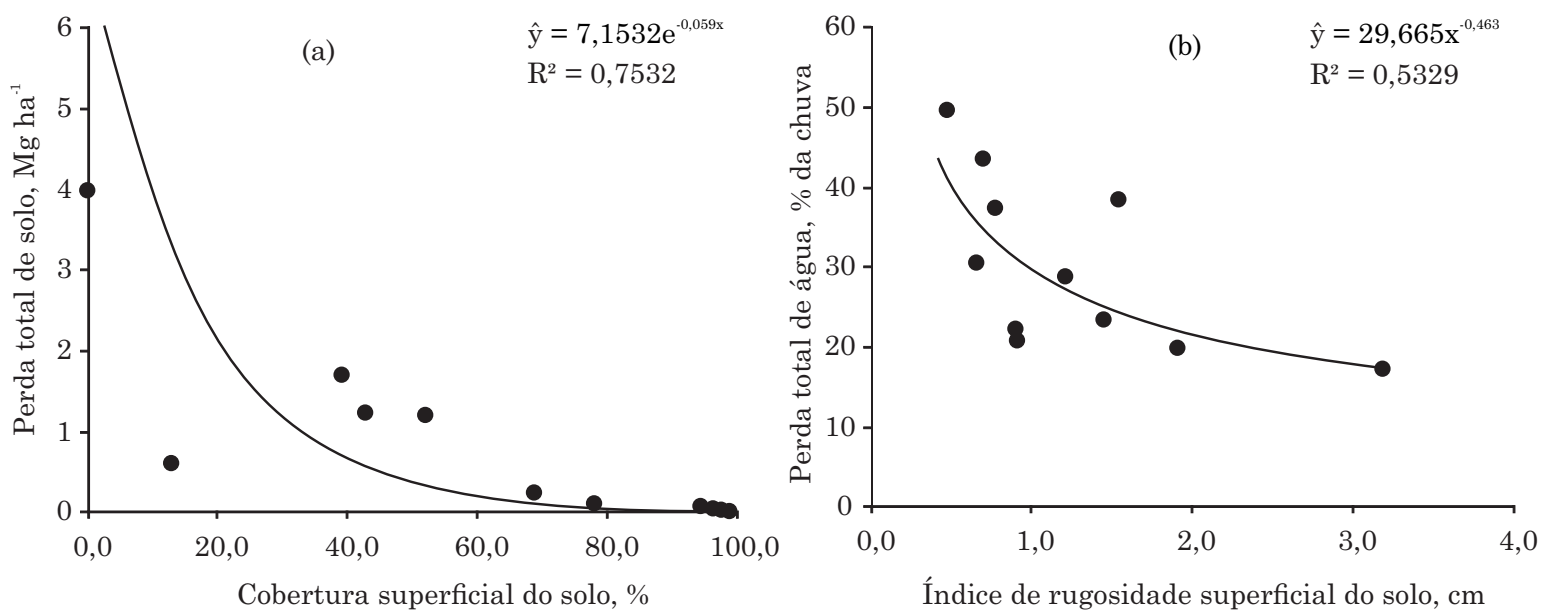

Figura 4. Relação da cobertura superficial do solo com sua perda total por erosão (a) e do seu de índice de rugosidade superficial com a perda total de água (b), nos tratamentos estudados.

resíduos culturais e perda total de solo e entre índice de rugosidade superficial do solo e perda total de água. Em relação aos dados da figura 4a, apesar dos baixos valores de perda de solo, essa se relacionou inversamente com a cobertura do solo por resíduos culturais e exponencialmente com sua rugosidade superficial, semelhante ao observado por Wischmeier \& Smith (1978), Cogo et al. (1983) e Leite et al. (2004). Em relação aos dados da figura $4 \mathrm{~b}$, observou-se que a perda total de água foi influenciada de modo inverso ao da perda de solo (modo potencial) na sua relação com o índice de rugosidade superficial do solo, o que também foi observado por Volk (2006), embora trabalhando com manejos de solo diferentes.

\section{CONCLUSÕES}

1. A rugosidade superficial do solo, criada pela operação de escarificação, retardou o início da enxurrada e aumentou a infiltração de água nele, consideravelmente reduzindo a perda de água por erosão, enquanto a sua cobertura pelos resíduos culturais remanescentes de aveia-preta e pelas plantas de milho expressivamente reduziu a sua perda pelo mesmo fenômeno.

2. A semeadora-adubadora de semeadura direta provida de facões ou hastes sulcadoras mobilizou o solo mais do que a desprovida desses órgãos (equipada apenas com sulcadores tipo discos-duplos desencontrados), diminuindo a perda de água ao redor de $35 \%$ e mantendo a perda de solo pequena.

3. No solo preparado convencionalmente e com cultivo, a sua perda por erosão foi maior no início da cultura, enquanto a perda de água foi maior no seu final.

\section{LITERATURA CITADA}

BERTOL, I.; AMARAL, A.J.; VAZQUEZ, E.V.; GONZALEZ, A.P.; BARBOSA, F.T. \& BRIGNONI, L.F. Relações da rugosidade superficial do solo com o volume de chuva e com a estabilidade de agregados em água. R. Bras. Ci. Solo, 30:543-553, 2006.

BERTOL, I.; COGO, N.P. \& LEVIEN, R. Relações da erosão hídrica com métodos de preparo do solo na ausência e na presença de cobertura por resíduo cultural de trigo. R. Bras. Ci. Solo, 11:187-192, 1987.

BURWELL, R.E.; ALLMARAS, R.R. \& AMEMIYA, M. A field measurement of total porosity and surface microrelief of soils. Soil Sci. Soc. Am. Proc., 27:696-700, 1963.

BURWELL, R.E.; ALLMARAS, R.R. \& SLONEKER, L.L. Structural alteration of soil surfaces by tillage and rainfall. J. Soil Water Conserv., 21:61-63, 1966.

CAMARA, R.C. \& KLEIN, V.A. Escarificação em plantio direto como técnica de conservação do solo e da água. R. Bras. Ci. Solo, 29:789-796, 2005.

CASTRO, L.G.; COGO, N.P. \& van LIER, Q.J. Índices de rugosidade superficial e sua correlação com perdas de solo. In: REUNIÃO BRASILEIRA DE MANEJO E CONSERVAÇÃO DO SOLO E DE ÁGUA, 13., Ilhéus, 2000. Anais...Viçosa, MG, SBCS, 2000. CD-ROM

CASTRO, L.G.; COGO, N.P. \& VOLK, L.B.S. Alterações na rugosidade superficial do solo pelo preparo e pela chuva e sua relação com a erosão hídrica. R. Bras. Ci. Solo, 30:339$352,2006$.

COGO, N.P. Effect of residue cover, tillage induce roughness, and slope length on erosion and related parameters. West Lafayette, Purdue University, 1981. 346p. (Tese de Doutorado)

COGO, N.P.; MOLDENHAUER, W.C. \& FOSTER, G.R. Soil loss reductions from conservation tillage practices as expressed by a mulch factor. Soil Sci. Soc. Am. J., 48:368$373,1984$. 
COGO, N.P.; MOLDENHAUER, W.C. \& FOSTER, G.R. Effect of residue cover, tillage-induced roughness, and runoff velocity on size distribution of eroded soil aggregates. Soil Sci. Soc. Am. J., 47:1005-1008, 1983.

ELTZ, F.L.F. \& NORTON, L.D. Surface roughness changes as affected by rainfall erosivity, tillage and canopy cover. Soil Sci. Soc. Am. J., 61:1746-1755, 1997.

EMPRESA BRASILEIRA DE PESQUISA AGROPECUÁRIA EMBRAPA. Recomendações gerais do encontro sobre o uso do simulador de chuva em pesquisa de Conservação do Solo no Brasil. In: ENCONTRO NACIONAL SOBRE PESQUISA DE EROSÃO COM SIMULADOR DE CHUVA, Londrina, 1975. Resumos... Londrina, IAPAR, 1975. p.107-120.

EMPRESA BRASILEIRA DE PESQUISA AGROPECUÁRIA . EMBRAPA. Centro Nacional de Pesquisa de Solos. Sistema brasileiro de classificação de solos. 2.ed. Rio de Janeiro, 2006. 306p.

GILlES, L.; COGO, N.P.; BISSANI, C.A.; BAGATINI, T. \& PORTELA, J.C. Perdas de água, solo, matéria orgânica e nutriente por erosão hídrica na cultura do milho implantada em área de campo nativo, influenciadas por métodos de preparo do solo e tipos de adubação. R. Bras. Ci. Solo, 33:1427-1440, 2009.

FISCHER, R.A. \& YATES, F. Tabelas estatiìsticas para biologia, medicina e agricultura. São Paulo, EDUSP, 1971. 150p.

HARTWIG, R.O. \& LAFLEN, J.M. A meterstick method for measuring crop residue cover. J. Soil Water Conserv., 33-32:90-91, 1978.

HERZOG, R.L.S.; LEVIEN, R. \& TREIN, C.R. Produtividade de soja em semeadura direta influenciada por profundidade do sulcador de adubo e doses de resíduo em sistema irrigado e não irrigado. Eng. Agríc., 24:771-780, 2004.

JOHNSON, C.B.; MANNERING, J.V. \& MOLDENHAUER, W.C. Influence of surface roughness and clod size and stability on soil and water losses. Soil Sci. Soc. Am. J., 43:772-777, 1979.

KAY, B.D. \& VAN DEN BYGAART, A.J. Conservation tillage and depth stratification of porosity and soil organic matter. Soil Till. Res., 66:107-118, 2002.

KLEIN, V.A.; BASEGGIO, M. \& MADALOSSO, T. Indicadores da qualidade física de um Latossolo Vermelho distrófico típico sob plantio direto escarificado. Ci. Rural, 39:2475$2481,2009$.

KÜIPERS, H. A reliefmeter of soil cultivation studies. Neth. J. Agric. Sci., 255-262, 1957.

LEITE, D.; BERTOL, I.; GUADAGNIN, J.C.; SANTOS, E.J. \& RITTER, S.R. Erosão hídrica em um Nitossolo Háplico submetido a diferentes sistemas de manejo sob chuva simulada. I - Perdas de solo e água. R. Bras. Ci. Solo, 28:1033-1044, 2004.
LEVIEN, R.; COGO, N.P. \& ROCKENBACH, C.A. Erosão na cultura do milho em diferentes sistemas de cultivo anterior e métodos de preparo do solo. R. Bras. Ci. Solo, 14:73-80, 1990.

LUCIANO, R.V.; BERTOL, I.; BARBOSA, F.T.; VÁZQUEZ, E.V. \& FABIAN, E.L. Perdas de água e solo por erosão hídrica em duas direções de semeadura de aveia e ervilhaca. R. Bras. Ci. Solo, 33:669-676, 2009.

MELLO, E.L.; BERTOL, I.; ZAPAROLLI, A.L.V. \& CARRAFA, M.R. Perdas de solo e água em diferentes sistemas de manejo de um Nitossolo Háplico submetido à chuva simulada. R. Bras. Cr. Solo, 27:901-909, 2003.

PANACHUKI, E.; BERTOL, I.; ALVES SOBRINHO, T.; VITORINO, A.C.T.; SOUZA, C.M.A. \& URCHEI, M.A. Rugosidade da superfície do solo sob diferentes sistemas de manejo e influenciada por chuva artificial. R. Bras. Ci. Solo, 34:443-441, 2010.

PORTELA, J.C.; COGO, N.P.; BAGATINI, T.; CHAGAS, J.P. \& PORTZ, G. Restauração da estrutura do solo por seqüências culturais implantadas em semeadura direta, e sua relação com a erosão hídrica em distintas condições físicas de superfície. R. Bras. Ci. Solo, 34:1353-1364, 2010.

RENARD, K.G.; FOSTER, G.R.; WEESIES, G.A.; McCOOL, D.K. \& YODER, D.C. Predicting soil erosion by water: A guide to conservation planning with the revised universal soil loss equation (RUSLE). Washington, USDA, 1997. 384p. (Agriculture Handbook, 703)

SWANSON, N.P. A rotating-boom rainfall simulator. Trans. ASAE, 26:1738-1743, 1965.

VOLK, L.B.S. Condições físicas da camada superficial do solo resultantes do seu manejo e indicadores de qualidade para redução da erosão hídrica e do escoamento superficial. Porto Alegre, Universidade Federal do Rio Grande do Sul, 2006. 148p. (Tese de Doutorado)

VOLK, L.B.S. \& COGO, N.P. Relações entre tamanho de sedimentos erodidos, velocidade da enxurrada, rugosidade superficial criada pelo preparo e tamanho de agregados em solo submetido a diferentes manejos. R. Bras. Ci. Solo, 33:1459-1471, 2009.

VOLK, L.B.S.; COGO, N.P. \& STRECK, E.V. Erosão hídrica influenciada por condições físicas de superfície e subsuperfície do solo, resultantes do seu manejo, na ausência de cobertura vegetal. R. Bras. Ci. Solo, 28:763$774,2004$.

WISCHMEIER, W.H. \& SMITH, D.D. Predicting rainfall erosion losses a guide to conservation planning. Washington, USDA, 1978. 58p. (Agriculture Handbook, 537)

WISCHMEIER, W.H \& SMITH, D.D. Rainfall energy and is relationship to soil loss. Trans. Am. Geophys. Union, 39:285-91, 1958. 